\title{
Desempenho de bezerros desmamados precocemente, mantidos em pastagem de capim elefante (Pennisetum purpureum, Schum), com diferentes níveis de suplementação
}

\author{
Evaluation performance of the steers in elefantegrass (Pennisetum purpureum Schum.) \\ with different levels of the supplementation
}

\author{
Luiz Giovani de Pellegrini' ${ }^{1}$ João Restle ${ }^{2}$ Mikael Neumann ${ }^{3}$ \\ Alexandre Nunes Motta de Souza ${ }^{4}$
}

\section{RESUMO}

Este experimento foi realizado na Região Central do Rio Grande do Sul, com o objetivo de avaliar o desempenho de bezerros de corte em sistema de pastejo contínuo em pastagem de capim-elefante (Pennisetum purpureum, Schum.) associado a diferentes níveis de suplementação: 0,$3 ; 0,7 ; 1,1$ e $1,5 \%$ do peso vivo dia ${ }^{-1}(P V)$. Foram utilizados 32 animais das raças Charolês (C), Nelore (N), 5/8 CN e 5/8 NC com idades médias de 120 dias, com pesos vivos médios iniciais de $98,5 \mathrm{~kg}$. O período de suplementação compreendeu 84 dias de avaliação, dividido em quatro períodos de 21 dias. A massa de forragem total da pastagem de capim-elefante apresentou $20,44 \%$ de matéria seca (MS), 10,67\% de proteína bruta (PB) e 7.006,0kg de MS ha durante o período experimental. Já a proporção de folhas verdes secas foi de $22,62 \%$, representando um total de folhas verdes secas de $1.650,8 \mathrm{~kg}$ de $M S \mathrm{ha} \mathrm{I}^{-1}$. Não houve interação $(P>0,05)$ entre nível de suplemento e período de avaliação para ganho de peso médio diário (GMD). Não houve diferença significativa entre os níveis de suplementação, mostrando GMD de 0,279, 0,380, 0,338 e 0,466kg dia para $0,3,0,7,1,1$ e 1,5\% do $P V$, respectivamente. Na análise dos períodos de suplementação, o GMD foi maior $(P<0,05)$ no terceiro período $\left(0,545 \mathrm{~kg}_{\text {dia }^{-1}}\right)$ e menor $(P<0,05)$ no quarto período $\left(0,145 \mathrm{~kg}\right.$ dia $\left.^{-1}\right)$ comparativamente ao primeiro $\left(0,342 \mathrm{~kg} \mathrm{dia}^{-1}\right)$ e ao segundo $\left(0,431 \mathrm{~kg} \mathrm{dia}^{-1}\right)$ períodos.

Palavras-chave: carga animal, forragem disponível, ganho de peso, pastagem de verão.

\section{ABSTRACT}

The experiment was conducted in Região Central do Rio Grande do Sul, in order to evaluate the performance of the steers in elefantegrass (Pennisetum purpureum Schum.), under continuous grazing associed with different sources supplementation: $0.3 ; 0.7 ; 1.1$ and $1.5 \%$ of live weight day ${ }^{-1}$ (LW). Thirty two Charolais (C), Nellore (N), 5/8 CN e 5/8 NC steers calves with na average age of one hundred twenty day, with average live weight of $98.5 \mathrm{~kg}$. The supplementation period was 84 days, divided in four periods of the 21 days. The forage mass of the pasture of elefantegrass presented average values of dry matter $20.44 \%$ (DM), crude protein $10.67 \%(C P) e$ $7.006 .0 \mathrm{~kg}$ de $\mathrm{DM}$ ha $\mathrm{a}^{-1}$ during experimental period. The proportion of green leaf matter was of $22.62 \%$ representation

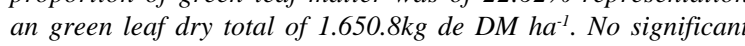
interaction was observed between sources supplementation and evaluation period for average weight gain (ADG). Observed what the ADG was of $0.365 \mathrm{~kg}$, no obtained significant difference between the sources, with ADG of $0.279,0.380,0.338$ e $0.466 \mathrm{~kg}$ day $^{-1}$ for $0.3,0.7,1.1$ e $1.5 \%$ do $L W$, respectively. In the analysis of the periods of supplementation, the GMD was bigger $(P<.05)$ in the third period $\left(0.545 \mathrm{~kg} \mathrm{day}^{-1}\right)$ and minor $(P<.05)$ in the fourth period $\left(0.145 \mathrm{~kg}^{\text {day }}{ }^{-1}\right)$ comparatively to the first $(0.342 \mathrm{~kg}$ $\left.d a y^{-1}\right)$ and to the second $\left(0.431 \mathrm{~kg} \mathrm{day}^{-1}\right)$ periods.

Key words: stocking rate, forage available, weight gain, summer pasture.

\section{INTRODUÇÃO}

A pecuária de corte do Rio Grande do Sul tem sua alimentação baseada na pastagem nativa, o que tem limitado substancialmente a produtividade do setor. Isso é causado pelas grandes variações que ocorrem nas condições climáticas durante as estações do ano, que afetam a quantidade e qualidade de forragem ofertada por esses ecossistemas. Sendo assim,

${ }^{1}$ Pós-graduação em Fitotecnia e Fitossanitarismo, Universidade Federal do Paraná (UFPR). Rua Benjamin Constant, 768, ap. 404, 97050-020, Santa Maria, RS, Brasil. E-mail: depellegrini@yahoo.com.br, Autor para correspondência.

${ }^{2}$ Pós-graduação em Zootecnia, Universidade Federal de Viçosa (UFV).

${ }^{3}$ Núcleo de Produção Animal, Curso de Medicina Veterinária, Universidade Estadual do Centro-Oeste (UNICENTRO), Paraná, Brasil.

${ }^{4}$ Pós-graduação em Zootecnia da Universidade Federal de Santa Maria. 
dificilmente a oferta de forragem se mantém constante durante o ano para satisfazer as necessidades dos animais (ROVIRA, 1996).

Essa variação na produção de forragem, associada a deficiências no manejo nutricional, sanitário e genético dos rebanhos de cria, faz com que se tenha baixos índices produtivos, destacando-se a baixa taxa de natalidade, que fica ao redor de $55 \%$, necessitandose de 1,8 vacas para se produzir 1 bezerro por ano (ANUALPEC, 2005), e ainda a elevada idade de entoure das fêmeas e elevada idade de abate dos machos.

O desmame precoce é uma das técnicas recomendadas quando se busca incrementar as taxas reprodutivas dos rebanhos de bovinos de corte, pois os nutrientes que seriam direcionados à produção de leite para a alimentação do bezerro passam a ser direcionados para a reposição das reservas do organismo da vaca, favorecendo na melhoria do seu estado corporal e na maior velocidade ao cio pós-parto (NEUMANN et al., 2005).

Se, por um lado, o desmame precoce favorece a vaca, deve-se ter o cuidado para não prejudicar o futuro desenvolvimento do bezerro. De acordo com RESTLE et al. (1999), o objetivo do desmame precoce não é promover ganhos de peso superiores aos obtidos ao pé da vaca, e sim promover um desenvolvimento que não prejudique o desempenho futuro do animal. Segundo os mesmos autores, quando o ganho de peso do bezerro desmamado precocemente é baixo, o seu futuro fica comprometido. Sendo assim, quando se realiza o desmame precoce, um dos cuidados que se deve ter é com a dieta que esses animais irão receber, pois se trata de uma categoria animal que necessita de maiores níveis nutricionais, sendo necessária a formulação de dietas que substituam o leite materno sem comprometer o desempenho animal.

A pastagem de capim-elefante, segundo PASCOAL \& RESTLE (2000), associada à prática de suplementação energética, pode aumentar consideravelmente a carga animal por hectare e suprir as exigências nutricionais dos bezerros. Dados de pesquisa mostram que bezerros desmamados precocemente não conseguem obter na pastagem de capim-elefante todos os nutrientes necessários para um desenvolvimento satisfatório (NEUMANN et al., 2005), sendo uma alternativa viável a suplementação com concentrados para tornar a dieta completa. Neste momento, a escolha do tipo e da quantidade do suplemento a ser utilizado deverá estar de acordo com os objetivos do sistema de produção.

Diante disso, o presente trabalho objetivou avaliar o efeito de diferentes níveis de suplemento energético sobre o desempenho de bezerros de corte desmamados precocemente, sob pastejo contínuo em pastagem de capim-elefante.

\section{MATERIAL E MÉTODOS}

O experimento foi desenvolvido na região central do Estado do Rio Grande do Sul, a uma altitude de $95 \mathrm{~m}$. O clima da região é o Cfa (subtropical úmido), conforme classificação de Köppen, com precipitação média anual de $1.769 \mathrm{~mm}$, temperatura média anual de $19,2^{\circ} \mathrm{C}$, com média mínima de $9,3^{\circ} \mathrm{C}$ em julho e média máxima de $24,7^{\circ} \mathrm{C}$ em janeiro, insolação de 2.212 horas anuais e umidade relativa do ar de $82 \%$ (MORENO, 1961).

O solo da área experimental é classificado como Argiloso vermelho distrófico arênico, pertencente à unidade de mapeamento São Pedro. A unidade caracteriza-se por apresentar solos de textura superficial arenosa e friável, sendo naturalmente ácidos, pobres em matéria orgânica e na maioria dos nutrientes, com baixa saturação de bases (EMBRAPA, 1999).

Foram selecionados 32 terneiros das raças Charolês (C), Nelore (N), 5/8 CN e 5/8 NC, nascidos entre 11/09/2001 a 18/12/2001, sendo estes desmamados em média com 35 dias de idade. Os bezerros, após o desmame, permaneceram 85 dias em confinamento, recebendo dieta completa até a pastagem de capim elefante apresentar condições de pastejo para o início do presente experimento.

A idade média dos animais no início do experimento foi de 120 dias, com peso vivo médio de $98,5 \mathrm{~kg}$ e escore de condição corporal de 2,6 (escala de 1 a 5 , sendo $1=$ muito magro e $5=$ muito gordo). Os animais foram distribuídos em 8 lotes de 4 animais cada (animais "testers"), sendo mantidos na pastagem de capim-elefante em sistema de pastejo contínuo, em piquetes de 0,5 ha cada, com carga variável. O pastejo contínuo foi adotado por intermédio da técnica "Putand-take" (MOOT \& LUCAS, 1952), utilizando quatro "testers" (C, N, 5/8 CN e 5/8 NC) e número variável de reguladores por piquete, com o objetivo de manter a oferta de forragem constante.

Os tratamentos foram constituídos de diferentes níveis de suplementação, sendo eles: 0,3; 0,$7 ; 1,1$ e $1,5 \%$ do peso vivo dia ${ }^{-1}$ (PV). O suplemento constituiu-se da mistura na proporção de $97 \%$ de farelo de trigo, $1,7 \%$ de calcário calcítico, $0,9 \%$ de fosfato bicálcico e $0,4 \%$ de sal comum mais adição de monensina sódica na proporção de $110 \mathrm{mg} \mathrm{an}^{-1} \mathrm{dia}^{-1}$, sendo fornecido diariamente às 14:00 horas. No período de adaptação, os animais foram vermifugados contra endo e ecto-parasitas. 
Durante o período experimental, a pastagem de capim-elefante recebeu adubação de cobertura de $160 \mathrm{~kg} \cdot \mathrm{ha}^{-1}$ de $\mathrm{N}$, na forma de uréia, dividida em duas aplicações, sendo a primeira realizada em $22 / 02$ e a segunda em 16/04/2002.

A massa de forragem foi avaliada a cada sete dias por meio da técnica de dupla amostragem (GARDNER, 1986). Três amostras foram cortadas rente ao solo $\left(0,5 \mathrm{~m}^{2}\right)$ e 15 avaliadas visualmente, por piquete. Das amostras coletadas de forragem, uma parte foi dessecada para determinação da composição botânica da planta: folhas verdes, folhas secas e colmo, sendo que a fração folha foi constituída de limbo foliar e bainha (NEUMANN et al., 2005), enquanto que a outra parte, juntamente com os componentes estruturais físicos segmentados da planta, foram pesados e pré-secados em estufa de ar forçado a $60^{\circ} \mathrm{C}$, por 72 horas, para determinação do teor de matéria parcialmente seca, conforme AOAC (1995). Posteriormente, as amostras pré-secadas foram moídas em moinho do tipo "Wiley”, com peneira de malha $2 \mathrm{~mm}$, e acondicionadas em potes plásticos, identificadas e submetidas às análises laboratoriais.

As análises laboratoriais foram realizadas no Departamento de Tecnologia de Alimentos da UFSM. Do componente estrutural folhas verdes secas foi determinado o teor de matéria seca total em estufa a $105^{\circ} \mathrm{C}$ e de proteína bruta (PB) pelo método micro Kjeldahl, segundo AOAC (1995).

A determinação da taxa de acúmulo diário da pastagem $\left(\mathrm{kg} \mathrm{ha}^{-1} \mathrm{dia}^{-1}\right)$ ocorreu em intervalos de 20 dias de avaliação, utilizando-se gaiolas de exclusão ao pastejo (1,2m de largura x 1,2m de comprimento x 2,0m de altura) teladas em malha de $8 \mathrm{~cm}$, segundo a técnica do tripo emparelhamento descrita por MORAES et al. (1990). Juntamente às avaliações da taxa de acúmulo diário da pastagem, determinou-se a altura da pastagem por meio de uma régua graduada.

Os animais foram pesados no início do período de adaptação, no início e no final do período de experimento, bem como a intervalos de 21 dias, mediante jejum de sólidos e líquidos de 12 horas. Simultaneamente às pesagens, foi avaliado o escore de condição corporal, seguindo a escala de um a cinco, conforme procedimento utilizado por RESTLE (1977).

Os ajustes da carga animal foram efetuados semanalmente com base na estimativa da massa de forragem de folha verdes secas residuais $\left(\mathrm{kg} \mathrm{ha}^{-1} \mathrm{dia}^{-1}\right)$. O ganho de peso médio diário (GMD) dos "testers" foi obtido pela diferença entre as pesagens realizadas no início e fim de cada período experimental, dividido pelo número de dias que os animais permaneceram na

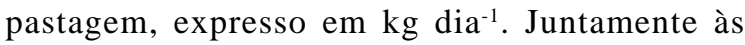

pesagens para determinação do GMD, foi determinado o escore de condição corporal (DC).

A carga animal foi obtida pelo somatório dos pesos de todos os animais presentes em cada piquete dividido pela área de cada piquete, sendo os valores expressos em $\mathrm{kg}_{\text {de }} \mathrm{PV} \mathrm{ha}{ }^{-1}$. A carga animal média dos períodos de utilização da pastagem foi obtida pela média aritmética da carga animal no início e fim desses períodos.

O delineamento experimental foi o inteiramente casualizado, composto por 4 tratamentos (níveis de suplementação: 0,3; 0,7; 1,1; 1,5\% PV), com duas repetições, em que cada unidade experimental constou de 1 piquete da pastagem de capim-elefante de 0,5 ha. As diferenças das médias foram realizadas por meio da análise de variância e a comparação das médias pelo teste Tukey ao nível de significância de $5 \%$, através do pacote estatístico SAS (1993). O modelo estatístico utilizado foi: $\mathrm{Y}_{\mathrm{ijk}}=\mu+\mathrm{NS}_{\mathrm{i}}+\mathrm{P}_{\mathrm{j}}+(\mathrm{NS} * \mathrm{P})_{\mathrm{ij}}+$ $\mathrm{E}_{\mathrm{ijk}}$, onde: $\mathrm{Y}_{\mathrm{ijk}}$ variáveis dependentes; $\mu=$ média das observações; $\mathrm{NSi}$ = efeito do níveis de suplemento de ordem “i”, sendo 1 (nível 0,3\% PV), 2 (nível 0,7\% PV), 3 (nível 1,1\% PV) e 4 (nível 1,5\% PV); $\mathrm{P}_{\mathrm{j}}=$ efeito do período de avaliação de ordem “j”, sendo 1 (primeiro período), 2 (segundo período), 3 (terceiro período) e 4 (quarto período); $(\mathrm{NS} * \mathrm{P})_{\mathrm{ij}}=$ efeito da interação entre o nível de suplemento de ordem “i”e período de avaliação de ordem “j”; $E_{\mathrm{ijk}}=$ erro aleatório residual. Os dados do GMD e do DC também foram submetidos à análise de regressão polinomial, considerando a variável período (dias) e o nível de suplementação (\% do PV) através do procedimento "proc reg" do programa SAS (1993).

\section{RESULTADOS E DISCUSSÃO}

Analisando os parâmetros avaliados, observa-se que não houve interação significativa entre níveis de suplementação $(0,3 ; 0,7 ; 1,1$ e $1,5 \%$ do peso vivo (PV)) e período de utilização da pastagem. Na tabela 1, são apresentadas as características quantitativas e qualitativas da massa de forragem da pastagem de capim elefante sob pastejo contínuo.

A permanência contínua dos animais "testers" recebendo os diferentes sistemas de alimentação, associada à lotação variável de animais controladores na pastagem, determinou uma massa de forragem média de $7.005,5 \mathrm{~kg} \mathrm{ha}^{-1}$ (Tabela 1). Esse resultado foi superior ao encontrado por KESSLER (1995) e MUEHLMANN (1993), que relataram resíduos médios de $3.608,0$ e $2.735,0 \mathrm{~kg}$ de $\mathrm{MS} \mathrm{ha}{ }^{-1}$, respectivamente. A participação de folhas na estrutura da pastagem também foi maior no presente trabalho, 
Tabela 1 - Massa de forragem (MF), massa de forragem de folhas verdes secas (MFFVS), taxa de acumulação média diária (TAMD), teores de matéria seca (MS) da massa de forragem (MF), do colmo (CM), das folhas verdes secas (FVS) e folhas secas (FS), proteína bruta $(\mathrm{PB})$ das folhas verdes secas e porcentagem dos componentes da massa de forragem por período de avaliação da pastagem de capim elefante em diferentes níveis de suplementação.

\begin{tabular}{|c|c|c|c|c|c|}
\hline \multirow{2}{*}{ Parâmetros } & \multicolumn{4}{|c|}{ Períodos de avaliação da pastagem } & \multirow{2}{*}{ Média } \\
\hline & $13 / 03$ a 03/04 & 04/04 a 24/04 & $25 / 04$ a $15 / 05$ & $16 / 05$ a $05 / 06$ & \\
\hline & \multicolumn{5}{|c|}{ Kg.ha ${ }^{-1}$} \\
\hline MF & $10.808,0$ & $6.343,0$ & $5.641,0$ & $5.230,0$ & $7.005,5$ \\
\hline MFFVS & $3.360,0$ & $1.441,0$ & 931,0 & 870,0 & $1.650,5$ \\
\hline TAMD & 198,3 & 103,8 & 110,0 & 27,1 & 109,8 \\
\hline Matéria seca: & & & $\%$ & & \\
\hline$-\mathrm{MF}$ & 20,99 & 19,79 & 19,53 & 21,45 & 20,44 \\
\hline$-\mathrm{CM}$ & 17,32 & 17,54 & 18,34 & 18,25 & 17,86 \\
\hline - FVS & 22,02 & 18,98 & 18,07 & 19,91 & 19,74 \\
\hline \multirow[t]{2}{*}{ - FS } & 67,15 & 62,59 & 66,68 & 74,73 & 67,78 \\
\hline & & & $\% \mathrm{MS}$ & & \\
\hline PB & 7,62 & 8,42 & 12,90 & 13,76 & 10,67 \\
\hline Componentes: & \multicolumn{5}{|c|}{ Composição Botânica (\%) } \\
\hline - Colmo & 51,1 & 60,3 & 64,9 & 68,6 & 61,2 \\
\hline - Folhas verdes secas & 33,7 & 23,7 & 16,5 & 16,8 & 22,6 \\
\hline - Folhas secas & 15,2 & 16,0 & 18,6 & 14,8 & 16,2 \\
\hline
\end{tabular}

com massa de forragem de folhas verdes secas de $1.650,5 \mathrm{~kg} \mathrm{ha}^{-1}$ (Tabela 1 ).

Observa-se que à taxa de acúmulo decresceu de 198,3 para $27,1 \mathrm{~kg} \mathrm{ha}^{-1} \cdot \operatorname{dia}^{-1}$ (Tabela 1) à medida que avançou-se do período primeiro para o quarto período de utilização da pastagem, sendo este comportamento resultante do efeito das condições climáticas, sendo que houve redução da temperatura associada à alta intensidade pluviométrica e à menor taxa de insolação diária com o avanço do período experimental de 13/03 a 05/06/2002. Segundo CARAMBULA (1996), o fotoperíodo, a intensidade de luz, a temperatura e o nível de umidade do solo associam-se diretamente à absorção de nutrientes e influenciam de forma notável os rendimentos de matéria seca. À medida que se diminui a intensidade de luz e a temperatura no período de outono/ inverno, o crescimento decresce até início da primavera, quando ocorre retomada de um novo ciclo produtivo.

Os teores de matéria seca (MS) da massa de forragem e dos componentes colmo, folhas verdes secas e folhas senescentes não variaram entre os tratamentos, com valores médios de 20,44; 17,86; 19,74 e 67,79\%, respectivamente (Tabela 1). Analisando-se o manejo da pastagem do capim-elefante, observou-se estabilidade nos teores de MS e aumentos crescentes nos teores de PB da massa da forragem disponível durante os períodos de utilização, respectivamente, com valores médios de 20,99 e 7,62\% no primeiro período, de 19,79 e 8,42\% no segundo período, de 19,53 e 12,90\% no terceiro período e de 21,45 e $13,76 \%$ no quarto período. Esta dinâmica no teor de MS da massa de forragem disponível foi determinada pelo componente estrutural folhas senescentes em função, respectivamente, de sua participação e de seu teor de MS na estrutura da planta (Tabela 1), observada no primeiro (15,21 e 67,15\%), segundo (16,00 e 62,59\%), terceiro $(18,64$ e $66,68 \%)$ e quarto $(14,76$ e $74,73 \%)$ períodos de avaliação.

Já o aumento crescente nos teores de PB da massa de forragem disponível justifica-se pelo comportamento dos animais, pois estes consumiram as folhas mais velhas que estavam presentes na estruturação da planta na fase inicial do experimento e, ao mesmo tempo, estimularam o rebrote das plantas associado a duas fertilizações em cobertura de nitrogênio (22/02 e 16/04/2002), que estimulam as plantas a perfilharem, melhorando a qualidade da forragem consumida, mesmo sob diminuição da taxa de acúmulo de MS com o avanço do período de utilização da pastagem na transição outono-inverno.

Resultados semelhantes são citados por KESSLER (1995), que explica o acréscimo pelo estímulo à rebrota e ao surgimento de afilhos após o pastejo inicial. Ainda NEUMANN et al. (2005) verificaram 
acréscimos nos valores de $\mathrm{PB}$ do primeiro $(7,01 \%)$ ao último período de avaliação $(8,15 \%)$, mas com valores abaixo do encontrado neste trabalho.

Analisando os componentes da composição botânica entre os períodos de avaliação (Tabela 1), observou-se que, com o avanço na utilização da pastagem, houve aumento e diminuição, respectivamente, de 51,11 e 33,67\% (primeiro período) para 68,56 e $16,81 \%$ (quarto período) na participação do componente colmo e folhas verdes secas.

RESTLEet al. (2001), avaliando o desempenho de bezerros desmamados precocemente, submetidos à suplementação energética em pastagem de capim-elefante, verificaram redução tanto na participação do componente colmo $(37,02 \%$ para $29,43 \%)$ como do componente folhas $(43,0 \%$ para $21,38 \%)$ na estrutura da planta em função do manejo utilizado. NEUMANN et al. (2005) também encontraram redução na participação dos componentes colmo (37,63 contra 31,33\%) e folhas (33,27 contra 20,61\%) na dinâmica da pastagem.

O incremento do nível de suplementação de 0,3 a $1,5 \%$ do PV não modificou o comportamento agronômico do capim-elefante, expresso em dados dos teores de MS e da composição da planta (Tabela 1), haja vista que o manejo da pastagem foi baseado na manutenção de uma disponibilidade de forragem e de folhas verdes secas equivalentes para todos os níveis de suplementação, através de ajustes semanais da carga animal (Tabela 2).

O manejo adotado para a pastagem de capim-elefante através da lotação variável dos animais nos diferentes piquetes possibilitou a disponibilidade de forragem similar do segundo ao quarto período (Tabela 1); no entanto, devido à redução da participação do componente folhas verdes secas na estrutura da pastagem, com o avanço dos períodos de utilização da pastagem (Tabela 1), constatou-se em um baixo desempenho animal, verificado diretamente no ganho de peso médio diário dos animais no último período de suplementação $\left(0,145 \mathrm{~kg} \mathrm{dia}^{-1}\right)$ (Tabela 2$)$.

Na média geral, animais suplementados ao nível de $0,3 \%$ do PV apresentaram menor GMD $(0,279 \mathrm{~kg}$ $\left.\mathrm{dia}^{-1}\right)$ em relação aos animais com níveis de suplementação de $0,7 \%$ do PV $\left(0,380 \mathrm{~kg} \mathrm{dia}^{-1}\right), 1,1 \%$ do PV $\left(0,338 \mathrm{~kg} \mathrm{dia}^{-1}\right)$ e de $1,5 \%$ do PV $\left(0,338 \mathrm{~kg} \mathrm{dia}^{-1}\right)$. O melhor desempenho dos animais recebendo os níveis maiores a $0,3 \%$ deve-se ao menor estresse dos animais frente às variações na quantidade e qualidade da massa de forragem disponível e da dinâmica da pastagem frente ao avanço de seu ciclo produtivo (Tabela 1), as quais estão, segundo NEUMANN et al. (2005), associadas à maior ingestão de MS e de nutrientes digestíveis totais contidos na fração concentrada ofertada aos animais.

Em relação aos períodos de utilização da pastagem, houve diferença estatística significativa para o GMD (Tabela 2). Os dados apresentados na tabela 2 mostram que o GMD foi crescente do primeiro $\left(0,342 \mathrm{~kg} \cdot \mathrm{dia}^{-1}\right)$ ao terceiro período $\left(0,545 \mathrm{~kg} \mathrm{dia}{ }^{-1}\right)$, reduzindo-se no quarto período $\left(0,145 \mathrm{~kg} \mathrm{dia}^{-1}\right)$, independentemente do nível de suplementação. O aumento no GMD do primeiro ao último período justifica-se pela maior oferta de forragem nestes

Tabela 2 - Ganho de peso médio diário (GMD) e carga animal (CA) dos bezerros de corte desmamados precocemente, por período de avaliação, sob pastejo contínuo em pastagem de capim elefante, submetidos a diferentes níveis de suplementação.

\begin{tabular}{|c|c|c|c|c|c|}
\hline \multirow{2}{*}{ Níveis de suplementação } & \multicolumn{4}{|c|}{ Períodos de avaliação da pastagem } & \multirow{2}{*}{ Média } \\
\hline & $13 / 03$ a $03 / 04$ & 04/04 a 24/04 & $25 / 04$ a $15 / 05$ & $16 / 05$ a $05 / 06$ & \\
\hline & \multicolumn{5}{|c|}{ GMD (kg PV.an $\left.{ }^{-1} \cdot \mathrm{dia}^{-1}\right)$} \\
\hline $0,3 \% \mathrm{PV}$ & 0,286 & 0,250 & 0,529 & 0,053 & $0,279 \mathrm{~B}$ \\
\hline $0,7 \% \mathrm{PV}$ & 0,375 & 0,452 & 0,493 & 0,202 & $0,380 \mathrm{~A}$ \\
\hline $1,1 \% \mathrm{PV}$ & 0,265 & 0,434 & 0,583 & 0,071 & $0,338 \mathrm{~A}$ \\
\hline $1,5 \% \mathrm{PV}$ & 0,442 & 0,589 & 0,577 & 0,256 & $0,466 \mathrm{~A}$ \\
\hline \multirow[t]{2}{*}{ Média } & $0,342 \mathrm{bc}$ & $0,431 \mathrm{ab}$ & $0,545 \mathrm{a}$ & $0,145 \mathrm{c}$ & \\
\hline & \multicolumn{5}{|c|}{ CA (kg PV.ha ${ }^{-1} \cdot$ dia $\left.^{-1}\right)$} \\
\hline $0,3 \% \mathrm{PV}$ & $1.813,7$ & $1.858,6$ & 910,5 & 959,5 & $1.385,6 \mathrm{~B}$ \\
\hline $0,7 \% \mathrm{PV}$ & $1.940,0$ & $2.004,6$ & 980,5 & $1.332,0$ & $1.564,4 \mathrm{AB}$ \\
\hline $1,1 \% \mathrm{PV}$ & $1.962,6$ & 2.263 .8 & $1.666,0$ & $1.756,0$ & $1.912,1 \mathrm{~A}$ \\
\hline $1,5 \% \mathrm{PV}$ & $1.855,9$ & $2.170,9$ & $1.944,0$ & $2.077,5$ & $2.012,1 \mathrm{~A}$ \\
\hline Média & $1.893,2 \mathrm{~b}$ & $2.074,4 \mathrm{a}$ & $1.375,2 \mathrm{~d}$ & $1.531,2 \mathrm{c}$ & \\
\hline
\end{tabular}

Médias seguidas de letras maiúsculas diferentes na coluna ou seguidas de letras minúsculas diferentes na linha diferem entre si pelo teste Tukey ao nível de significância de $5 \%$. 
períodos, principalmente do componente folhas verdes secas, com reflexo direto no desenvolvimento corporal $(98,52$ para $120,25 \mathrm{~kg})$ e escore de condição corporal (2,60 para 3,03) dos animais (Tabela 3). Já no quarto período, a redução na oferta de folhas verdes secas proporcionou a redução no GMD.

Valores superiores em desempenho animal foram observados por NEUMANN et al. (2005), trabalhando com bezerros e bezerras desmamados precocemente em pastagem de capim-elefante sob diferentes níveis de suplementação energética, com ganho médio geral de $0,730 \mathrm{~kg} \mathrm{dia}^{-1}$, apesar de estarem trabalhando com oferta de folhas verdes secas de $1.003,1 \mathrm{~kg} \mathrm{ha}^{-1}$, inferior à deste trabalho. Já ALMEIDA (1997), trabalhando com diferentes ofertas de forragem, sem suplementação, em pastagem de capim-elefante, obteve ganhos de 0,907 a $1,055 \mathrm{~kg} \mathrm{dia}^{-1}$, com massa de forragem de folhas verdes secas variando de 1.420,0 a $5.551,0 \mathrm{~kg} \mathrm{ha}^{-1}$.

A carga animal acresceu em função do aumento do nível de suplementação, havendo diferença estatística significativa entre os tratamentos (Tabela 2). O nível $0,3 \%$ do PV permitiu carga animal de $1.385,6 \mathrm{~kg}$ de PV ha ${ }^{-1} \mathrm{dia}^{-1}$, diferindo dos níveis 1,1 e 1,5\% do PV, que suportaram $1.912,1$ e $2.012,1 \mathrm{~kg}$ de PV ha-1 $\mathrm{dia}^{-1}$, respectivamente. Mesmo não havendo diferença ( $P>0,05)$ na carga animal entre os níveis de suplementação superiores a 0,7, 1,0 e 1,5\% do PV, observou-se incrementos relativos na ordem de $22,2 \%$ e de $28,6 \%$ na carga animal, com os níveis 1,1 e 1,5\% do $\mathrm{PV}$, respectivamente, em relação ao nível $0,7 \%$ do PV.
Dentre os períodos de utilização da pastagem, a maior carga animal $(\mathrm{P}<0,05)$ obtida foi observada no segundo período (2.074,4kg de PV ha ${ }^{-1} \mathrm{dia}^{-1}$ ) e a menor $(\mathrm{P}<0,05)$ no terceiro período $(1.375,2 \mathrm{~kg}$ de $\mathrm{PV}$ $\left.\mathrm{ha}^{-1} \mathrm{dia}^{-1}\right)$, justificando-se esta oscilação pela variação no crescimento da pastagem e pelo incremento do desenvolvimento corporal dos animais (Tabela 3), associado às limitações ambientais de alta umidade e baixa intensidade de horas luz .

$\mathrm{Na}$ análise do desenvolvimento animal, o incremento no nível suplemento mostrou o efeito substitutivo da forragem consumida pelo suplemento ofertado, o que incrementou a carga animal. No entanto, o incremento no nível de suplemento não teve efeito aditivo, visto que não houve diferença no GMD dos animais, apesar de os animais suplementados ao nível de $1,5 \%$ do PV terem GMD de 59,87\% superior ao nível 0,3\% do PV.

$\mathrm{Na}$ análise global do sistema produtivo, o desenvolvimento corporal e o escore corporal (Tabela $3)$ dos animais aumentou $(\mathrm{P}<0,05)$ frente aos períodos de suplementação. Do início ao final da suplementação, que durou 84 dias, observou-se um incremento de $30,79 \mathrm{~kg}$ no peso vivo dos animais, independentemente do nível de suplementação. Ainda analisando-se a tabela 3, observou-se que o ganho de peso total foi similar $(\mathrm{P}>0,05)$ no período de 84 dias de suplementação para os níveis 0,7, 1,1 e 1,5\% (28,46; 32,01 e 39,17kg, respectivamente), em relação ao nível $0,3 \%$ do PV $(23,52 \mathrm{~kg})$.

Para o escore de condição corporal (ECC), não houve diferença significativa entre os níveis de

Tabela 3 - Desenvolvimento corporal e escore de condição corporal (ECC) de bezerros de corte desmamados precocemente, sob pastejo contínuo em pastagem de capim-elefante, submetidos a diferentes níveis de suplemento, conforme as datas de avaliação.

\begin{tabular}{|c|c|c|c|c|c|c|}
\hline \multirow{2}{*}{ Níveis de suplementação } & \multicolumn{5}{|c|}{ Datas de avaliação da pastagem } & \multirow{2}{*}{ Média } \\
\hline & 13/03 Peso inicial & 03/04 & $24 / 05$ & $15 / 05$ & 05/06 Peso final & \\
\hline & \multicolumn{6}{|c|}{ Desenvolvimento Corporal (kg.animal $\left.{ }^{-1}\right)$} \\
\hline $0,3 \% \mathrm{PV}$ & 96,98 & 103,00 & 108,25 & 119,37 & 120,50 & $109,62 \mathrm{~A}$ \\
\hline $0,7 \% \mathrm{PV}$ & 99,99 & 107,87 & 117,37 & 127,75 & 132,00 & $116,99 \mathrm{~A}$ \\
\hline $1,1 \% \mathrm{PV}$ & 97,91 & 103,50 & 112,62 & 124,87 & 126,37 & $113,05 \mathrm{~A}$ \\
\hline $1,5 \% \mathrm{PV}$ & 99,20 & 108,50 & 120,87 & 133,00 & 138,37 & $119,99 \mathrm{~A}$ \\
\hline Média & \multicolumn{6}{|c|}{$\mathrm{ECC}\left(\right.$ pontos) ${ }^{1}$} \\
\hline $0,3 \% \mathrm{PV}$ & 2,56 & 2,65 & 2,76 & 2,94 & 2,86 & $2,75 \mathrm{~A}$ \\
\hline $0,7 \% \mathrm{PV}$ & 2,60 & 2,69 & 2,85 & 3,05 & 3,04 & $2,84 \mathrm{~A}$ \\
\hline $1,1 \% \mathrm{PV}$ & 2,63 & 2,70 & 2,78 & 2,96 & 2,90 & $2,79 \mathrm{~A}$ \\
\hline $1,5 \% \mathrm{PV}$ & 2,60 & 2,79 & 2,97 & 3,19 & 3,10 & $2,93 \mathrm{~A}$ \\
\hline Média & $2,60 \mathrm{~d}$ & $2,70 \mathrm{c}$ & $2,84 \mathrm{~b}$ & $3,03 \mathrm{a}$ & $2,97 \mathrm{a}$ & \\
\hline
\end{tabular}

1 - escore de condição corporal: 1 = muito magro, 2 = magro, 3 = médio, 4 = gordo e 5 = muito gordo (Restle, 1977).

Médias, seguidas de letras maiúsculas diferentes na coluna ou seguidas de letras minúsculas diferentes na linha diferem entre si pelo teste Tukey ao nível de significância de $5 \%$. 
suplementação. O ECC acompanhou a evolução do GMD dos bezerros e, conseqüentemente, o desenvolvimento corporal, sendo maior para aqueles que apresentaram maior GMD no período. A habilidade em alterar a condição corporal de animais em pastejo, segundo POPPI \& McLENNAN (1995), depende única e exclusivamente da dieta que estes animais estão consumindo, associada às características químicas e estruturais da pastagem utilizada.

\section{CONCLUSÕES}

Aumentos nos níveis de suplementação não propiciaram aumentos no ganho de peso de bovinos jovens pastejando capim-elefante. O nível de suplementação de $1,5 \%$ do peso vivo foi o que determinou maior carga animal e manteve-se constante durante o período de utilização da pastagem. No manejo da pastagem de capim-elefante, dificilmente mantémse a oferta de folhas verdes secas constante, devido à dinâmica de crescimento da planta frente às condições climáticas.

\section{REFERÊNCIAS}

ALMEIDA, E.X. Oferta de forragem de capim elefante anão (Pennisetum purpureum Schum.) cv. Mott, dinâmica da pastagem e sua relação com o rendimento animal no Alto Vale do Itajaí, Santa Catarina. 1997. 108f. Tese (Doutorado em Agronomia-Zootecnia) - Curso de Pósgraduação da Universidade Federal do Rio Grande do Sul.

ANUALPEC. Anuário da pecuária brasileira. FNP Consultoria \& Comércio. São Paulo: Argos, 2005. 392p.

ASSOCIATION OF OFFICIAL ANALYTICAL CHEMISTS AOAC. Official methods of analysis. 16.ed. Washington, DC., 1995. 2000p

CARAMBULA, M. Pasturas naturales mejoradas Montevideo: Hemisfério Sur, 1996. 524p.

EMPRESA BRASILEIRA DE PESQUISA AGROPECUÁRIA EMBRAPA. Centro Nacional de Pesquisa do Solo - CNPS. Sistema Brasileiro de Classificação de solos. Rio de Janeiro: EMBRAPA, 1999. 412p.

GARDNER, A.L. Técnicas de pesquisa em pastagem e aplicabilidade de resultados em sistemas de produção. Brasília: IICA/EMBRAPA_CNPGL, 1986. 197p. (IICA, Série publicações Miscelâneas, 634).

KESSLER, J.P.M.C. Pastejo continuo em capim-elefante (Pernisetum purpureum, Schum) com vacas em lactação, sob níveis distintos de folha residual. 1995. $137 \mathrm{f}$.
Dissertação (Mestrado em Zootecnia) - Curso de Pós-graduação da Universidade Federal de Santa Maria.

MOOT, G.O., LUCAS, H.L. The design conduct and interpretation of grazing trials on cultivated and improved pastures. In: INTERNATIONAL GRASSLAND CONGRESS, 6., 1952, Pensylvania. Poceedings... Pensylvania: State College, 1952. p.1380-1395.

MORAES, A. et al. Comparação de métodos de estimativa de taxas de crescimento em uma pastagem submetida a diferentes pressões de pastejo. In: REUNIÃO ANUAL DA SOCIEDADE BRASILEIRA DE ZOOTECNIA, 27., 1990, Campinas, SP. Anais... Piracicaba: FEALQ, 1990. p.332.

MORENO, J.A. Clima do Rio Grande do Sul. Porto Alegre: Secretaria da Agricultura, 1961. 41p.

MUEHLMANN, L.D. Desempenho de terneiras desmamadas precocemente, quando submetidas a diferentes tipos de pastagem no pós-desmame. 1993. 106f. Dissertação (Mestrado em Zootecnia) - Curso de Pósgraduação da Universidade Federal de Santa Maria.

NEUMANN, M. et al. Desempenho de bezerros de corte em pastagem de capim elefante (Pennisetum purpureum Schum.) associado a diferentes níveis de suplementação. Ciência Rural, v.35, n.1, p.157-163, 2005 .

PASCOAL, L.L.; RESTLE, J. Deferentes sistemas de alimentação para desmame aos 60 - 90 dias - Desempenho e economicidade. In: RESTLE, J. Eficiência na produção de bovinos de corte. Santa Maria: UFSM - Departamento de Zootecnia, 2000. Cap.9, p.258-276.

POPPI, D.P.; McLENNAN, S.R. Protein and energy utilization by ruminants at pasture. Journal of Animal Science, v.73, n.1, p.278-290, 1995

RESTLE, J. Estado corporal e desempenho reprodutivo em vacas de corte. In: REUNIÃO DA SOCIEDADE BRAZILEIRA DE ZOOTECNIA, 14., 1977, Viçosa. Anais... Viçosa: SBZ, 1977. p.107.

RESTLE, J. et al. Desempenho de terneiros desmamados aos 60-90 dias, submetidos a diferentes níveis de suplementação em pastagem de capim-elefante. In: REUNIÃO ANUAL DA SOCIEDADE BRASILEIRA DE ZOOTECNIA, 38., 2001, Piracicaba. Anais... São Paulo: Sociedade Brasileira de Zootecnia/Gnosis, [2001]. 17par, p.1351-1352.

RESTLE, J. et al. Desemvolvimento de bovinos de corte de diferentes grupos genéticos desmamados aos 3 ou 7 meses de idade. Revista da Sociedade Brasileira de Zootecnia, v.28, n.5, p.1023-1030, 1999.

ROVIRA, J. Campo natural: forrajeira del rodeio de cria. Manejo nutritivo de los rodeios de cria en pastoreo. Montevidéo: Hemisfério Sur, 1996. Cap.5, p.51-65.

SAS INSTITUTE. SAS/STAT user's guide: statistics. 4.ed. Version 6. Cary, NC, 1993. V.2, 943p. 